\title{
Article \\ Identifying Running Deviations in Long Distance Runners Utilizing Gait Profile Analysis: A Case Control Study
}

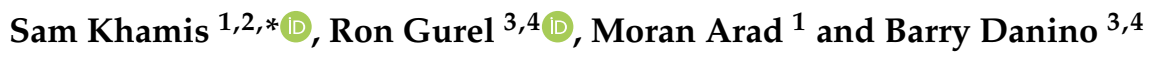 \\ 1 Gait and Motion Analysis Laboratory, Department of Pediatric Orthopedics, Dana Children's Hospital, \\ Tel-Aviv Sourasky Medical Center, Tel-Aviv 64239, Israel; arad.moran@gmail.com \\ 2 Imacs-Israeli Motion Analysis Center for Sports, Tel-Aviv 6492807, Israel \\ 3 Department of Pediatric Orthopedics, Dana Children's Hospital, Tel-Aviv Sourasky Medical Center, 6, \\ Weizmann St., Tel-Aviv 64239, Israel; rongurel@gmail.com (R.G.); barrydanino@hotmail.com (B.D.) \\ 4 Sackler Faculty of Medicine, Tel-Aviv University, Tel-Aviv 6997801, Israel \\ * Correspondence: khamisam@gmail.com
}

Citation: Khamis, S.; Gurel, R.; Arad, M.; Danino, B. Identifying Running Deviations in Long Distance Runners Utilizing Gait Profile Analysis: A Case Control Study. Appl. Sci. 2021, 11, 10898. https://doi.org/ 10.3390/app112210898

Academic Editors: Claudio Belvedere and Arkady Voloshin

Received: 6 October 2021

Accepted: 16 November 2021

Published: 18 November 2021

Publisher's Note: MDPI stays neutral with regard to jurisdictional claims in published maps and institutional affiliations.

Copyright: (c) 2021 by the authors. Licensee MDPI, Basel, Switzerland. This article is an open access article distributed under the terms and conditions of the Creative Commons Attribution (CC BY) license (https:// creativecommons.org/licenses/by/ $4.0 /)$.

\begin{abstract}
Objective: The goal of this study was to utilize Gait Profile Score (GPS) and Gait Deviation Index (GDI), to assess its capability of differentiating between injured and non-injured runners. Design: In total, 45 long-distance runners (15 non-injured, 30 injured), diagnosed with one of the following running related injuries, patella femoral pain syndrome, iliotibial pain syndrome, and medial tibial stress syndrome, were recruited. Methods: Data were obtained from a running analysis gait laboratory equipped with eight infrared motion-capturing cameras and a conventional treadmill. Running kinematics were recorded according to the Plug-In Gait model, measuring running deviations of the pelvis and lower extremities at a sampling rate of $200 \mathrm{~Hz}$. GPS and GDI were calculated integrating pelvis and lower limb kinematics. Movement Analysis Profile results were compared between injured and non-injured runners. The non-parametric two-sample Wilcoxson test determined whether significant kinematic differences were observed. Results: Total GPS score significantly differed between the injured and non-injured runners. Not all running kinematics expressed by GDI differed between groups. Conclusions: GPS score was capable of discriminating between the injured and non-injured runners' groups. This new running assessment method makes it possible to identify running injuries using a single numerical value and evaluate movements in individual joints.
\end{abstract}

Keywords: running; gait analysis; injury; kinematics; Gait Profile Score (GPS)

\section{Introduction}

Running is one of the most popular forms of physical activity in Western countries [1] and one of the most efficient ways to achieve physical fitness [2], reduce risk factors for cardiovascular disease [3], generate weight loss, and improve cognitive performance [4]. A major drawback of this sport is the high risk of running-related injuries. Several studies have shown an injury incidence of $19-79 \%$ per year $[1,2,4]$. The knee is the most common site of lower extremity injuries in runners, followed by the lower leg [5]. Running injuries have been found to be related to several intrinsic factors, including leg length discrepancy [6], running techniques [2], and abnormal limb biomechanics [2,7].

Gait analysis can be expressed in a single score by the Gait Deviation Index (GDI) and the Gait Profile Score (GPS) [8,9]. The GPS, introduced by Baker et al. [8], summarizes the overall deviation of kinematic gait data from normative data. This single index provides gait variable scores to the nine key component kinematic gait variables that comprise the GPS score. The movement analysis profile (MAP) is a graph consisting of 10 columns; nine representing each gait variable, and the tenth equaling the GPS score. The GPS as well as the GDI are represented by the same units $\left(^{\circ}\right)$ as the kinematic variables, but as these scores denote the distance from the normal average, the smaller values indicate less deviation 
from the norm or better results. In the literature, the GPS has been found to be a valid tool reflecting the quality of the gait pattern in several pathologies, including multiple sclerosis, Parkinson's disease, and cerebral palsy [10-12].

The Gait Deviation Index (GDI), a methodology described by Schwartz in 2008 [9], incorporates nine features, including three-dimensional rotation angles for the pelvis and the hip, the sagittal plane at the knee, and the sagittal plane at the ankle, as well as the foot progression angle. Kinematic variables include pelvic obliquity, tilt and rotation, hip $\mathrm{ab} /$ adduction, flexion/extension, rotations, knee flexion/extension, ankle dorsi/plantar flexion, and foot progression angle.

Patella femoral pain syndrome (PFPS), iliotibial band syndrome (ITBS), and medial tibial stress syndrome (MTSS) are some of the most common injuries observed in long distance runners [7]. PFPS commonly presents as a gradual onset of knee pain in the area of the patella and is associated with patellofemoral loading activities such as running and squatting. A diagnosis is usually formulated by past history and a physical examination, rarely requiring imaging studies [13]. ITBS, characterized by lateral knee pain in the active athletic population, is typically diagnosed by past history and a physical examination without requiring imaging studies. Possible etiologies are friction of the iliotibial band against the lateral femoral epicondyle, compression of the deep fat and connective tissues in the region, and the chronic inflammation of the iliotibial band bursa [14]. MTSS, also known as shin splints, present as pain or discomfort in the area around the lower half of the medial tibia. Diffuse tenderness over the posteromedial border of the tibia is the most sensitive sign [15-18].

It has been suggested that PFPS is linked to several lower limb malalignments such as increased peak hip adduction [19], internal rotation, and contralateral pelvic drop [20]. Other studies have reported inconsistent results or no correlations between hip, knee kinematics, and injury $[15,17,18]$. In Barton et al.'s systematic review, the authors presented conflicting findings as to hip internal rotation and its correlation to patellofemoral pain [17]. Bolgla et al. discovered that subjects with PFPS demonstrated a significant hip weakness, but, no altered hip and knee kinematics (measured during a standardized stair-stepping task), as previously theorized [18]. ITBS was found to be associated with increased knee internal rotation and hip adduction in female runners [15], however, other previous studies have established that it is related to maximum knee flexion, maximum knee internal rotation velocity, maximum foot inversion, and maximum ankle extension [21,22]. Several studies have concluded that shod runners prone to ITBS, may use abnormal segmental coordination patterns, particularly, with couplings involving thigh adduction/abduction and tibial internal/external rotation [21,22].

The biomechanical cause of MTSS is still inconclusive. One case-control study found that individuals with a history of shin splints demonstrated a significantly greater frontal plane pelvic tilt, peak hip internal rotation, and less knee flexion compared to a matched group of runners without pain [23]. In contrast, Newman et al. in their systematic review, found no correlation between biomechanical factors and shin splints in runners, and an increased hip external rotation range of motion (ROM) and navicular drop as statistically significant risk factors of MTSS [24].

According to the above findings, treatment strategies have addressed these faulty biomechanics by altering running techniques and applying functional training corrections [25-27]. Napier et al. reported that lower limb running injuries have been linked to several abnormal biomechanical factors [27], however, currently, there is no consensus for a specific biomechanical deviation leading to injury. Moreover, previous studies have not found any evidence to support a correlation between abnormal biomechanics and running $[15,17]$. The inconsistency regarding the relationship between deviations and injury might be due to a combination of several biomechanical deviations and kinematic variables that must be taken into consideration as a cause of injury. Three-dimensional kinematics quantify the overall deviation of an individual's gait or run from a normal gait or run. 
A biomechanical running analysis, used in sports as a diagnostic tool, assists in the understanding of the kinematics of a wide range of variables throughout the running cycle, as well as detecting abnormal biomechanics. Currently, as yet, no single score has been ascertained to identify running deviations. Such a score can be used for classifying running deviations with a single numeric value, based on pelvis lower limb kinematics, as well as identifying movement patterns which are risk factors for running injuries. We hypothesized that injured long distance runners might present with kinematic differences during running that would most likely be reflected by differences in GPS and GDI, subsequently identifying runners who are more prone to developing sport-related injuries.

\section{Materials and Methods}

\subsection{Study Design and Participants}

A total of 45 (15 non-injured and 30 injured) long distance recreational runners participated in the study. Fifteen non-injured, average age of 28 (SD 1.9; range 26-32) and body mass index (BMI) of 24.7 (SD 1.4), and 30 injured, average age of 30 (SD 1.7; range 28-33), and a BMI of 23.6 (SD 1.5), were randomly selected, retrospectively, from a gait and running analysis laboratory database between the years 2015-2019. Inclusion criteria included a diagnosis of at least one of the following running-related injuries: PFPS, ITBS, or MTSS (Table 1). Their referring orthopedic clinician and physical therapists determined diagnoses. The subjects underwent a clinical evaluation by the main investigator (SK).

Table 1. Runners' injuries.

\begin{tabular}{cccccc}
\hline & N $=30$ & Bilateral & Left & Right & Sex (F/M)_ \\
\hline PFPS & 12 & 4 & 4 & 4 & $\mathrm{~F}=4 ; \mathrm{M}=8$ \\
ITBS & 10 & - & 5 & 5 & $\mathrm{~F}=5 ; \mathrm{M}=5$ \\
MTSS & 8 & 8 & - & - & $\mathrm{F}=3 ; \mathrm{M}=5$ \\
\hline Patella femoral pain syndrome (PFPS), iliotibial pain syndrome (ITBS), medial tibial stress syndrome (MTSS).
\end{tabular}

Lower limb measures of ROM and muscle-tendon length were performed by a universal standard plastic goniometer, with muscle strength measured by manual muscle testing [28]. No significant abnormal clinical findings were noted on their physical evaluation, such as limited ROM, short muscle tendon, or muscle weakness. Excluded from the study were runners unfamiliar with treadmill running and if pain was provoked during the running evaluation. The study was approved by the Tel Aviv Sourasky Medical Center, Tel Aviv, Israel's Ethics Committee (0055-20-TLV).

Data were collected from a running analysis gait laboratory equipped with eight infrared motion capturing cameras (Bonita, Vicon Motion Systems, Ltd., Oxford, UK) and a conventional treadmill used for running. The data were recorded according to the Plug-In Gait Model (PGM) [29], using Cardan angles, measuring running deviations of the pelvis and lower extremities with a sampling rate of $200 \mathrm{~Hz}$. Fifteen reflective passive skin markers were placed on the subjects' pelvis and lower limbs according to the PGM protocol. On the pelvis, markers were placed on the anterior superior iliac spine and sacrum, lateral thigh, lateral knee, lateral shank, lateral ankle, heel, and forefoot bilaterally (Figure 1). Participants ran barefoot to rule out any effect of their running shoes and at their own self-selected speed. Six running cycles were chosen for further analysis. Subjects were given up to $7 \mathrm{~min}$ to acclimate to running barefoot and to establish a comfortable running speed prior to the data capture for an additional $5 \mathrm{~min}$. They were instructed to report pain and to cease running if pain developed during the running session. 


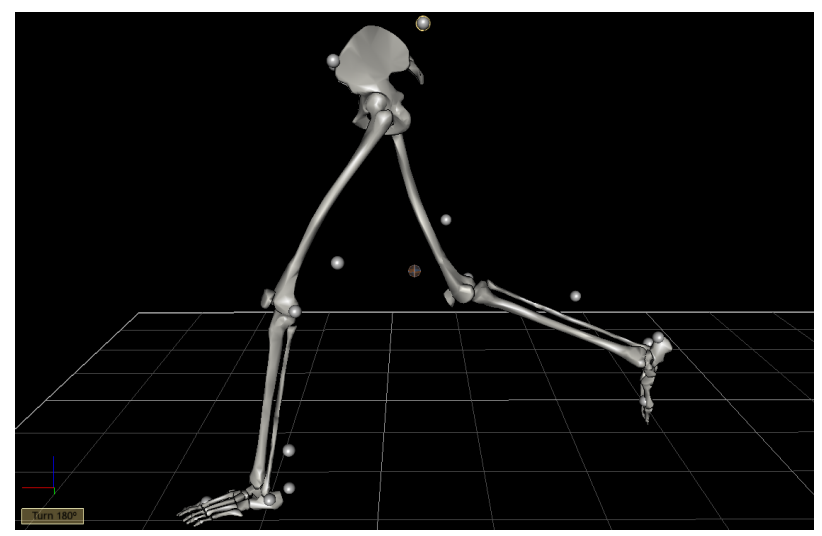

Figure 1. An example of a VICON Motion System skeletal image of a runner from the injured group with marker placement (anterior superior iliac spine, sacrum, lateral thigh, lateral knee, lateral shank, lateral ankle, heel, and forefoot bilaterally).

\subsection{Data Reduction and Analysis}

All trials were filtered using the Woltring filtering routine with a predicted mean squared error of 10 as per our standards of practice. GPS and GDI were calculated based on the proposal of Baker et al. [30]. These indices have been previously validated [8,9]. MAP results were compared between the injured and non-injured distance runners. The GDI is based on the calculation of the distance between the patient's data and the average taken from the reference dataset of 15 gait features of gait kinematics of the pelvis, hip, knee, and ankle [8,9]. The GPS is obtained from the same gait kinematics as the GDI and is calculated on all gait kinematics, representing the root mean square difference between the patient's data and the average taken from the reference dataset $[8,9]$.

\subsection{Statistical Analysis}

Shapiro-Wilk test was used to test for normality of the distribution. The non-parametric two-sample Wilcoxson test determined whether there were significant kinematic differences in the groups' GDI and GPS scores. $p$-values were corrected by the Benjamini-Hochberg procedure, thus, guaranteeing a false discovery rate control of 0.05 per measure. Statistical analysis was done using R (Version 3.4), an open-source statistical language and data analysis tool.

\section{Results}

No significant differences were found between the groups as to age, weight, height, and BMI. The self-selected running speed for the non-injured group was an average of $10.4 \mathrm{~km} / \mathrm{h}$ (individual subject speeds ranging from 9.8 to $11.5 \mathrm{~km} / \mathrm{h}$ ), and an average of $10.6 \mathrm{~km} / \mathrm{h}$ (individual subject speeds ranging from 9.6 to $11.4 \mathrm{~km} / \mathrm{h}$ ) for the injured group. The GDI scores were comparable between the non-injured group (Nig) and the injured group (Ig) $(p>0.05)$ for anterior/posterior pelvic tilt $(p=0.175)$, hip flexion/extension (Left $p=0.141$; Right $p=0.130$ ), and pelvis obliquity (Left $p=0.500$; Right $p=0.433$ ) (Figure 2). Significant sagittal plane differences were observed when performing right knee flexion/extension (GDI-Nig 6.3, GDI-Ig 9.7; $p=0.008$ ) and left ankle dorsi/plantar flexion (GDI-Nig 5.0, GDI-Ig 9.3; $p=0.000$ ) and frontal plane differences were seen during left hip abduction/adduction (GDI-Nig 2.9, GDI-Ig 4.4; $p=0.044$ ). Rotational plane differences were observed during left pelvis internal/external rotation (GDI-Nig 1.9, GDI-Ig 3.3; $p=0.003$ ) and right (GDI-Nig 2.7, GDI-Ig 3.9; $p=0.021$ ), during left hip internal/external rotation (GDI-Nig 4.9, GDI-Ig 7.7; $p=0.019$ ) and right (GDI-Nig 5.0, GDI-Ig 7.7; $p=0.008$ ) and right internal/external foot rotation (GDI-Nig 5.2, GDI-Ig 10.6; $p=0.000$ ). The GPS score significantly differed between groups, both on the left and right side (GPS-Nig 5.5, GPS-Ig $7.1 ; p=0.003$; GPS-Nig 5.3, GPS-Ig 7.5; $p=0.000$, respectively), furthermore, the overall 
GPS also significantly differed (GPS-Nig 5.7, GPS-Ig 7.8; $p=0.000$ ) (Table 2). Pelvis and lower limb kinematics are presented in Figure 3.

Table 2. Mean and standard deviation of GDI and GPS results of the injured and non-injured running groups $(p<0.05)$.

\begin{tabular}{|c|c|c|c|c|}
\hline & \multicolumn{4}{|c|}{ GDI } \\
\hline & & $\begin{array}{l}\text { Non-Injured } \\
\text { [SD] (Degrees) }\end{array}$ & $\begin{array}{c}\text { Injured [SD] } \\
\text { (Degrees) }\end{array}$ & $p$-Value \\
\hline \multirow{2}{*}{$\begin{array}{c}\text { Hip flex- } \\
\text { ion/extension }\end{array}$} & Left & $5.3[1.9]$ & $6.8[2.6]$ & 0.141 \\
\hline & Right & $5.24[1.2]$ & $6.5[2.3]$ & 0.130 \\
\hline \multirow{2}{*}{$\begin{array}{l}\text { Knee flex- } \\
\text { ion/extension }\end{array}$} & Left & $7.8[2.4]$ & $9.5[2.9]$ & 0.255 \\
\hline & Right & $6.3[2.9]$ & $9.7[3.4]$ & $0.008^{* *}$ \\
\hline \multirow{3}{*}{$\begin{array}{c}\text { Ankle } \\
\text { dorsi/plantar } \\
\text { flexion }\end{array}$} & Left & $5.0[3.5]$ & $9.3[2.9]$ & $0.000^{* *}$ \\
\hline & Right & $7.9[1.9]$ & 9.4 [3.4] & 0.181 \\
\hline & Left & $2.2[0.9]$ & $2.4[1.0]$ & 0.500 \\
\hline Pelvis up/down & Right & $2.2[0.9]$ & $2.5[1.1]$ & 0.433 \\
\hline \multirow{2}{*}{$\begin{array}{c}\text { Hip abduc- } \\
\text { tion/adduction }\end{array}$} & Left & $2.9[1.0]$ & $4.4[2.0]$ & $0.044^{*}$ \\
\hline & Right & $3.1[1.3]$ & $4[2.0]$ & 0.229 \\
\hline $\begin{array}{l}\text { Pelvis ante- } \\
\text { rior/posterior }\end{array}$ & Overall & $4.9[1.6]$ & $4.3[2.8]$ & 0.175 \\
\hline \multirow{2}{*}{$\begin{array}{l}\text { Pelvic inter- } \\
\text { nal/external }\end{array}$} & Left & $1.9[0.8]$ & $3.3[1.4]$ & 0.003 \\
\hline & Right & $2.7[1.0]$ & $3.9[1.7]$ & 0.021 \\
\hline \multirow{2}{*}{$\begin{array}{l}\text { Hip inter- } \\
\text { nal/external }\end{array}$} & Left & $4.9[1.5]$ & $7.7[3.7]$ & $0.019 *$ \\
\hline & Right & $5.0[2.6]$ & $7.7[4.2]$ & $0.008^{* *}$ \\
\hline \multirow{6}{*}{$\begin{array}{c}\text { Foot inter- } \\
\text { nal/external }\end{array}$} & Left & 8.5 [3.1] & $8.1[3.9]$ & 0.634 \\
\hline & Right & 5. [1.8] & $10.6[4.9]$ & $0.000^{* * *}$ \\
\hline & \multicolumn{4}{|c|}{ GPS } \\
\hline & Left & $5.5[0.8]$ & $7.1[1.6]$ & 0.003 ** \\
\hline & Right & $5.3[0.8]$ & $7.5[1.6]$ & $0.000^{* * *}$ \\
\hline & Overall & $5.7[0.8]$ & $7.8[1.6]$ & $0.000^{* * *}$ \\
\hline
\end{tabular}

Gait deviation index (GDI), Gait Profile Score (GPS) ${ }^{*} p \leq 0.05{ }^{* * *} p \leq 0.01{ }^{* * * *} p \leq 0.001$.

\section{Movement Analysis Profile}

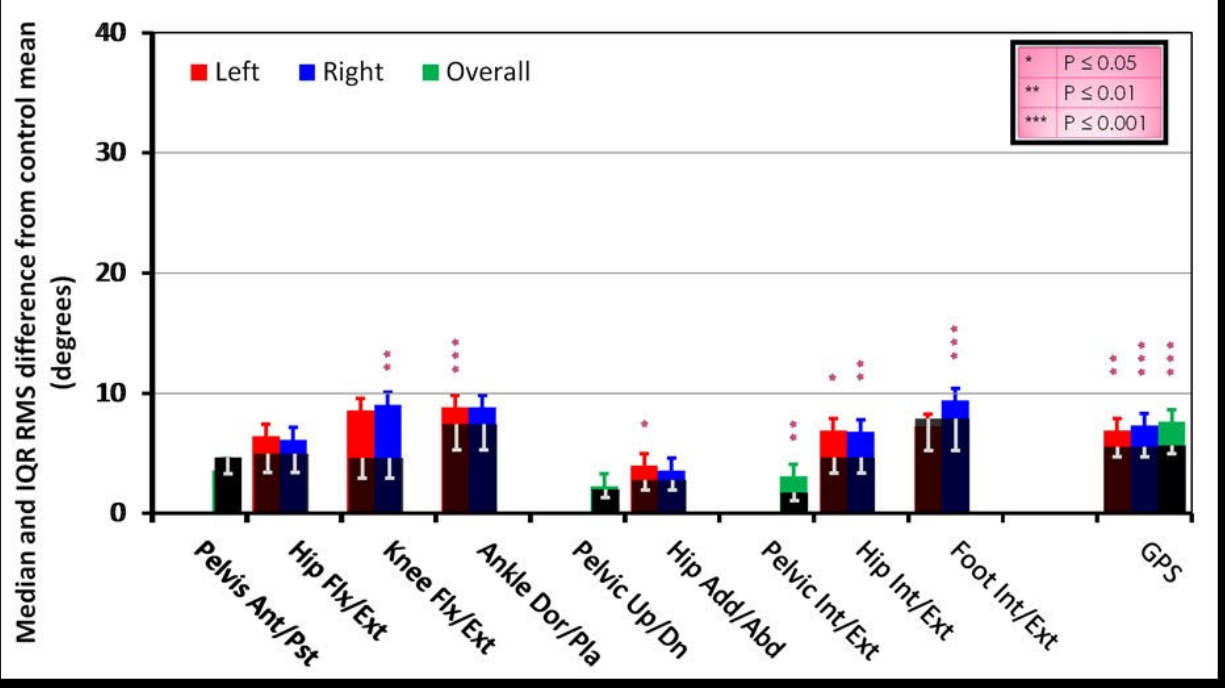

Figure 2. Movement Analysis Profile: median and interquartile range (IQR) root mean square (RMS) 
difference from control mean. Injured runners: left in red, right in blue, overall in green. Non-injured runners in black. Pelvis Ant/pst—Anterior/Posterior Pelvic tilt; Hip Flx/Ext—Hip Flexion/Extension; Knee Flx/Ext—Knee Flexion/Extension; Ankle Dor/Pla—Ankle Dorsiflexion/Plantar flexion; Pelvic Up/Dn—Pelvic Obliquity; Hip Add/Abd-Hip Adduction/Abduction; Pelvic Int/Ext-Pelvic Internal/External Rotation; Hip Int/Ext-Hip Internal/External Rotation; Foot Int/Ext—Foot Internal/External progression angle. $(p<0.05)$. ${ }^{*} p \leq 0.05 ;{ }^{* *} p \leq 0.01 ;{ }^{* * *} p \leq 0.001$.

\section{Pelvis and lower limb kinematics}
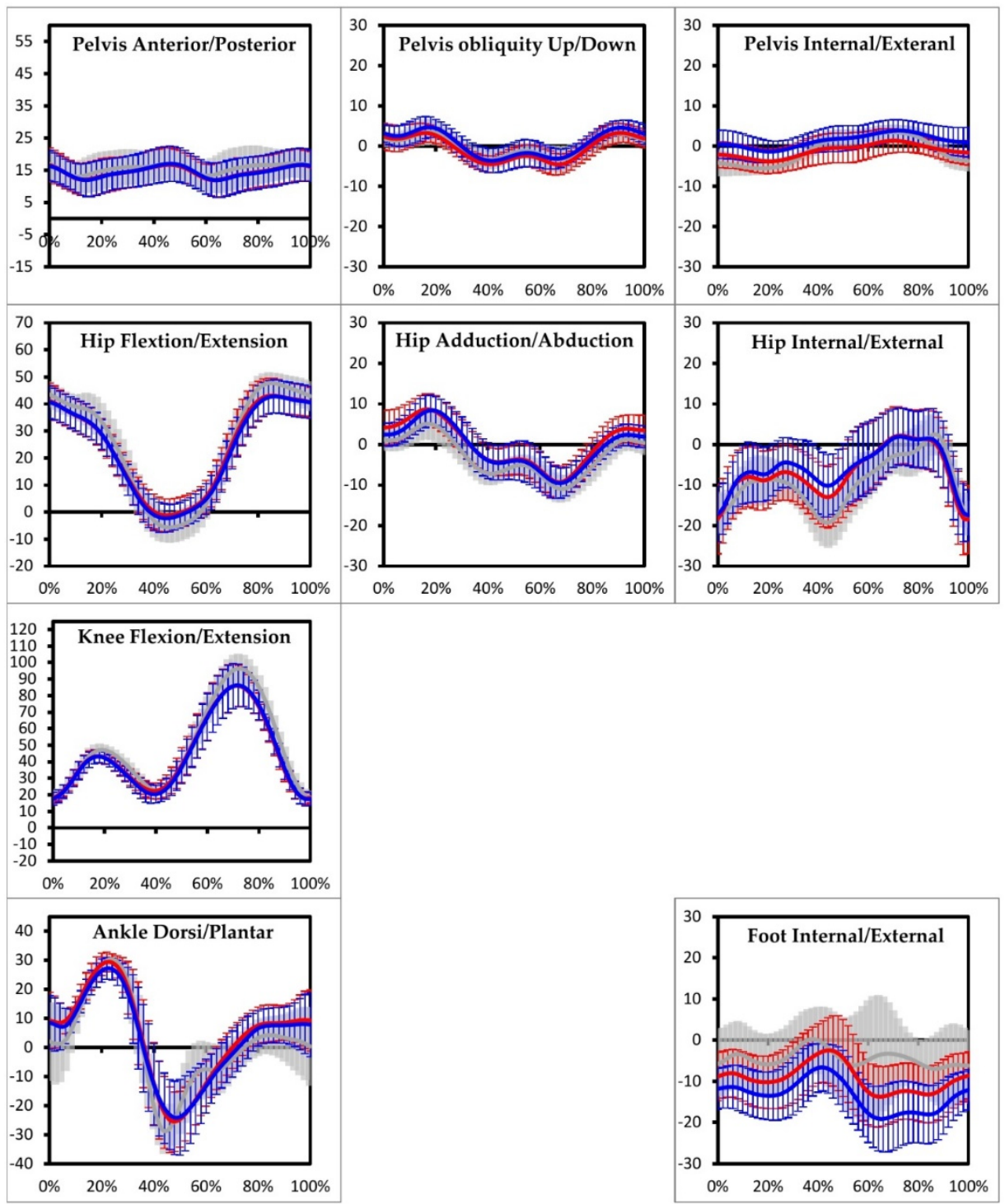

Figure 3. Pelvis and lower limb kinematics of injured and non-injured running groups: injured group; left in red, right in blue. Non-injured group in grey.

\section{Discussion}

Significant kinematic differences were found between injured and non-injured runners as exhibited by their GPS score. Not all gait kinematic changes expressed by the GDI differed. The total GPS score detected differences between both groups. The sum of all GDI's differences, significant or not found during the gait cycle, indicated differences in the total GPS score, implying that the GPS score was capable of kinematic discrimination between the injured and non-injured runners' groups. The motion of the pelvis was found to be relatively the same in both groups, contrary to Davis et al. who argued that injured 
runners with PFPS might present with a more backward trunk lean [25], and thus, we would expect to find differences in the sagittal plane pelvic tilt. Our findings did not correlate with previous studies where pelvic obliquity was a significant contributing factor to running injuries $[15,20]$. Neal et al. found that a contralateral pelvic drop correlated with PFPS [20]. In another systematic review, the authors found that female runners with ITBS increased their peak trunk ipsilateral during stance [15]. In our study, pelvic obliquity was not a contributing factor. Pelvic rotation differed between the groups, with higher GDI values that had not been previously documented, but the excessive pelvic rotation can be explained as a strategy to increase step length [31] or as weaker muscular support leading to poor pelvic rotational control by the injured runners.

Hip adduction was found to have higher GDI values only on the left, however, hip rotation presented with higher values on both sides. These findings correlate with previous studies emphasizing the role of hip adduction and rotation in running injuries $[15,20,24,31]$. Neal et al. in their cross-sectional study of mixed sex cohorts found moderate evidence supporting a correlation between PFPS during running and increased hip adduction and internal rotation [20]. However, they found very limited prospective evidence that increased hip adduction is a risk factor for PFPS in female runners or that running retraining changes symptoms and function in runners [20]. Aderem and Louw [15] concluded in their systematic review that female runners who developed ITBS presented with increased peak hip adduction and increased peak knee internal rotation during stance.

A systemic literature review study aimed at identifying the biomechanical variables involved in the etiology of ITBS [32]. The authors demonstrated that runners with a history of ITBS appear to exhibit decreased hip adduction angles at heel strike while exhibiting decreased total abduction/adduction ROM at the hip during stance phase. They concluded that greater internal rotation of the knee joint and increased hip adduction angles, may play a role in the etiology of ITBS. These findings support Davis et al.'s conclusions who emphasized addressing the motor program in order to change the motor pattern, including excessive hip adduction, by using biofeedback training in treating patellofemoral pain [25].

In our sudy, we found that GDI values differed in the sagittal plane and were higher amongst the injured group in right knee flexion/extension, and left ankle dorsi/plantar flexion. These findings suggest that sagittal plane kinematics might also be a contributing factor to running injuries. Generally, sagittal plane deviations are unrelated to running injuries. Our findings correlate with two studies that also found significant associations between PFPS and sagittal plane deviations, reduced stance phase peak hip flexion [20,33]. However, according to the GDI values in our study, we cannot identify the specific running phase at which the deviation occurred. Foot rotation is determined by the rotational profile of the lower limb and foot pronation/supination movement [34]. Differences were found only on the right, which might imply more hyperpronation of the right foot. Okunuki et al. found that foot malalignment has been correlated to running injuries, specifically MTSS [35].

Our results are consistent with Loudon and Reiman who also found hip internal rotation and knee sagittal plane movement to be correlated with MTSS [23]. However, in our study, frontal plane kinematics was not found to be associated with MTSS.

GPS values were found to differ on both sides, implying that kinematic deviations are not determined or correlated to the injured side. Thus, we can assume that the total movement pattern differs between both groups. This finding correlates with Rees et al. who found no difference in knee valgus angle between the painful and pain-free side as well as between the dominant and non-dominant sides [36], and Brown et al. [37], who found that lower limb dominance did not affect kinematic side to side differences. These findings imply that lower limb kinematics during running are relatively symmetrical. They question asymmetry as the cause of injury, rather imply that the general running pattern, which is reflected by the total lower limb kinematics, leads to running injuries. The GDI differed in all three planes of motion, but not in all joints, and were not correlated to the injured side. This might imply that a single difference at one level, unilaterally, might be insignificant, 
however, it may become significant if the sum of all deviations in all joints, in more than one plane of motion, leads to a significant total change in the lower limb alignment, reflected by the GPS. This may explain the conflicting findings of several researchers who found no correlation between single kinematic deviations and injuries [32,38]. Ceyssens et al. in their systematic review, found no conclusive biomechanical mechanism to explain the development of running related injuries [38] and concluded that current prospective evidence relating biomechanical variables to running-related injury risk is scarce and inconsistent, with findings largely dependent on the population and injuries being studied. Furthermore, Louw and Deary [32] reported that it is unlikely that abnormal biomechanics of the foot or tibia are responsible for increasing tension in the ITB; there was most likely a more proximal cause. They stated that their review had very limited prospective evidence, and therefore, the results should be interpreted with caution [32].

Our results might imply that correction of kinematic deviations, reflected by gait indices, may be another tool to consider in management of running injuries, targeting either a major correction at one level or several minor corrections in order to lead to changes in the GPS, and improve symptoms. This is consistent with Napier et al. who reported an improvement in symptoms due to a change in several kinematic deviations, thus, concluding that many biomechanical parameters can be altered by running modification training programs and that these interventions can change the kinetic, kinematic, and spatiotemporal outcomes during running [27]. Another study found that neuromuscular training with knee valgus control instructions reduced kinetics, and injury incidence in male runners and improved kinematics [26]. Furthermore, Davis et al. in their systematic review found that faulty movement patterns are associated with patellofemoral pain. They discovered that movement retraining (retraining faulty patterns) plays a significant role in addressing patellofemoral pain [25].

This study investigated a small sample of the running population, however, it presented a new perspective for evaluating kinematic deviations in runners. GPS should be implemented in the future, identifying running deviations using a single numerical value and evaluating movement in individual joints, both clinically and in research. Validity of this score will be based on its capability of identifying injured runners and their running deviation leading to the injury, and may also be used as a possible indicator for detecting running injury risk factors. Future research should, as well, evaluate the changes in the GPS post running re-education and its influence on symptoms. One restriction of the GPS is that it does not measure all foot kinematics, such as hind foot kinematics, an important factor in running injuries, rather it only measures the foot progression angle. In addition, a limitation of this study is the absence of demographic data that may have an impact on running injuries such as previous running injuries, shoe type, and running terrain.

It is essential to say that the MAP score in our study presents deviations among injured runners. However, it is impossible to declare the cause and effect relationship. Those deviations may be merely a reflection of the injury.

\section{Conclusions}

The correlation and causative factors between running injuries and kinematic deviations is still questionable, probably because several minor kinematic deviations must occur simultaneously in order to cause injury. The GPS is capable of integrating kinematic deviations into one score. In our study, by evaluating this score, we were able to differentiate between injured and uninjured runners, thus, suggesting integrating this measurement into studies to detect and possibly prevent running injuries based on the running profile.

Author Contributions: Conceptualization, S.K. and B.D.; methodology, S.K.; validation, R.G. and M.A.; formal analysis R.G. and M.A.; investigation, R.G. and M.A.; data curation, S.K.; writingoriginal draft preparation, R.G.; writing-review and editing M.A., S.K. and B.D.; visualization, S.K. and B.D.; supervision, S.K. and B.D.; project administration, S.K. and B.D.; funding acquisition, N/A. All authors have read and agreed to the published version of the manuscript. 
Funding: This research received no external funding.

Institutional Review Board Statement: The study was conducted according to the guidelines of the Declaration of Helsinki was approved by the Tel Aviv Sourasky Medical Center, Tel Aviv, Israel's Ethics Committee (0055-20-TLV).

Informed Consent Statement: Not applicable.

Acknowledgments: The authors thank Phyllis Curchack Kornspan for her editorial services.

Conflicts of Interest: The authors declare no conflict of interest.

\section{References}

1. Fokkema, T.; Burggraaff, R.; Hartgens, F.; Kluitenberg, B.; Verhagen, E.; Backx, F.J.G.; van der Worp, H.; Bierma-Zeinstra, S.M.A.; Koes, B.W.; van Middelkoop, M. Prognosis and prognostic factors of running-related injuries in novice runners: A prospective cohort study. J. Sci. Med. Sport 2019, 22, 259-263. [CrossRef] [PubMed]

2. van der Worp, M.P.; ten Haaf, D.S.; van Cingel, R.; de Wijer, A.; van der Sanden, M.W.N.; Staal, J.B. Injuries in runners; a systematic review on risk factors and sex differences. PLoS ONE 2015, 10, e0114937.

3. Lopes, A.D.; Hespanhol Júnior, L.C.; Yeung, S.S.; Costa, L.O. What are the Main Running-Related Musculoskeletal Injuries? Sports Med. 2012, 42, 891-905. [CrossRef] [PubMed]

4. Berchtold, N.C.; Castello, N.; Cotman, C.W. Exercise and time-dependent benefits to learning and memory. Neuroscience 2010, 167, 588-597. [CrossRef]

5. van Gent, R.N.; Siem, D.; van Middelkoop, M.; van Os, A.G.; Bierma-Zeinstra, S.M.; Koes, B.W. Incidence and determinants of lower extremity running injuries in long distance runners: A systematic review. Br. J. Sports Med. 2007, 41, 469-480. [CrossRef]

6. $\quad$ Fields, K.B.; Sykes, J.C.; Walker, K.M.; Jackson, J.C. Prevention of running injuries. Curr. Sports Med. Rep. 2010, 9, 176-182. [CrossRef]

7. Taunton, J.E.; Ryan, M.B.; Clement, D.B.; McKenzie, D.C.; Lloyd-Smith, D.R.; Zumbo, B.D. A retrospective case-control analysis of 2002 running injuries. Br. J. Sports Med. 2002, 36, 95-101. [CrossRef]

8. Baker, R.; McGinley, J.L.; Schwartz, M.H.; Beynon, S.; Rozumalski, A.; Graham, H.K.; Tirosh, O. The gait profile score and movement analysis profile. Gait Posture 2009, 30, 265-269. [CrossRef]

9. Schwartz, M.H.; Rozumalski, A. The Gait Deviation Index: A new comprehensive index of gait pathology. Gait Posture 2008, 28, 351-357. [CrossRef]

10. Holmes, S.J.; Mudge, A.J.; Wojciechowski, E.A.; Axt, M.W.; Burns, J. Impact of multilevel joint contractures of the hips, knees and ankles on the Gait Profile score in children with cerebral palsy. Clin. Biomech. 2018, 59, 8-14. [CrossRef]

11. Pau, M.; Caggiari, S.; Mura, A.; Corona, F.; Leban, B.; Coghe, G.; Lorefice, L.; Marrosu, M.G.; Cocco, E. Clinical assessment of gait in individuals with multiple sclerosis using wearable inertial sensors: Comparison with patient-based measure. Mult. Scler. Relat. Disorders. 2016, 10, 187-191. [CrossRef]

12. Speciali, D.S.; Corrêa, J.C.; Luna, N.M.; Brant, R.; Greve, J.M.; de Godoy, W.; Baker, R.; Lucareli, P.R. Validation of GDI, GPS and GVS for use in Parkinson's disease through evaluation of effects of subthalamic deep brain stimulation and levodopa. Gait Posture 2014, 39, 1142-1145. [CrossRef]

13. Crossley, K.M.; Callaghan, M.J.; van Linschoten, R. Patellofemoral pain. Br. J. Sports Med. 2016, 50, 247-250. [CrossRef] [PubMed]

14. Strauss, E.J.; Kim, S.; Calcei, J.G.; Park, D. Iliotibial band syndrome: Evaluation and management. J. Am. Acad. Orthop. Surg. 2011, 19, 728-736. [CrossRef] [PubMed]

15. Aderem, J.; Louw, Q.A. Biomechanical risk factors associated with iliotibial band syndrome in runners: A systematic review. BMC Musculoskelet. Disord. 2015, 16, 356. [CrossRef] [PubMed]

16. Alfayez, S.M.; Ahmed, M.L.; Alomar, A.Z. A review article of medial tibial stress syndrome. J. Musculoskelet. Surg. Res. 2017, 1, 2-5.

17. Barton, C.J.; Levinger, P.; Menz, H.B.; Webster, K.E. Kinematic gait characteristics associated with patellofemoral pain syndrome: A systematic review. Gait Posture 2009, 30, 405-416. [CrossRef]

18. Bolgla, L.A.; Malone, T.R.; Umberger, B.R.; Uhl, T.L. Hip strength and hip and knee kinematics during stair descent in females with and without patellofemoral pain syndrome. J. Orthop. Sports Phys. Ther. 2008, 38, 12-18. [CrossRef]

19. Souza, R.B.; Powers, C.M. Differences in hip kinematics, muscle strength, and muscle activation between subjects with and without patellofemoral pain. J. Orthop. Sports Phys. Ther. 2009, 39, 12-19. [CrossRef]

20. Neal, B.S.; Barton, C.J.; Gallie, R.; O'Halloran, P.; Morrissey, D. Runners with patellofemoral pain have altered biomechanics which targeted interventions can modify: A systematic review and meta-analysis. Gait Posture 2016, 45, 69-82. [CrossRef]

21. Miller, R.H.; Lowry, J.L.; Meardon, S.A.; Gillette, J.C. Lower extremity mechanics of iliotibial band syndrome during an exhaustive run. Gait Posture 2007, 26, 407-413. [CrossRef] [PubMed]

22. Miller, R.H.; Meardon, S.A.; Derrick, T.R.; Gillette, J.C. Continuous relative phase variability during an exhaustive run in runners with a history of iliotibial band syndrome. J. Appl. Biomech. 2008, 24, 262-270. [CrossRef]

23. Loudon, J.K.; Reiman, M.P. Lower extremity kinematics in running athletes with and without a history of medial shin pain. Int. J. Sports Phys. Ther. 2012, 7, 356-364. [PubMed] 
24. Newman, P.; Witchalls, J.; Waddington, G.; Adams, R. Risk factors associated with medial tibial stress syndrome in runners: A systematic review and meta-analysis. Open Access J. Sports Med. 2013, 4, 229-241. [CrossRef]

25. Davis, I.S.; Tenforde, A.S.; Neal, B.S.; Roper, J.L.; Willy, R.W. Gait retraining as an intervention for patellofemoral pain. Curr. Rev. Musculoskelet. Med. 2020, 13, 103-114. [CrossRef]

26. Letafatkar, A.; Rabiei, P.; Afshari, M. Effect of neuromuscular training augmented with knee valgus control instructions on lower limb biomechanics of male runners. Phys. Ther. Sport 2020, 43, 89-99. [CrossRef]

27. Napier, C.; Cochrane, C.K.; Taunton, J.E.; Hunt, M.A. Gait modifications to change lower extremity gait biomechanics in runners: A systematic review. Br. J. Sports Med. 2015, 49, 1382-1388. [CrossRef]

28. Naqvi, U.; Sherman, A.L. Muscle Strength Grading. 2020 Sep 3. In StatPearls [Internet]; StatPearls Publishing: Treasure Island, FL, USA, 2020.

29. Charalambous, C.P. Measurement of lower extremity kinematics during level walking. In Classic Papers in Orthopaedics; Banaszkiewicz, P., Kader, D., Eds.; Springer: London, UK, 2014; pp. 397-398.

30. Baker, R.; McGinley, J.L.; Schwartz, M.; Thomason, P.; Rodda, J.; Graham, H.K. The minimal clinically important difference for the Gait Profile Score. Gait Posture 2012, 35, 612-615. [CrossRef]

31. Liang, B.W.; Wu, W.H.; Meijer, O.G.; Lin, J.H.; Lv, G.R.; Lin, X.C.; Prins, M.R.; Hu, H.; van Dieën, J.H.; Bruijn, S.M. Pelvic step: The contribution of horizontal pelvis rotation to step length in young healthy adults walking on a treadmill. Gait Posture 2014, 39, 105-110. [CrossRef]

32. Louw, M.; Deary, C. The biomechanical variables involved in the aetiology of iliotibial band syndrome in distance runnersA systematic review of the literature. Phys. Ther. Sport 2014, 15, 64-75. [CrossRef] [PubMed]

33. Bazett-Jones, D.M.; Cobb, S.C.; Huddleston, W.E.; O'Connor, K.M.; Armstrong, B.S.R.; Earl-Boehm, J.E. Effect of patellofemoral pain on strength and mechanics after an exhaustive run. Med. Sci. Sports Exerc. 2013, 45, 1331-1339. [CrossRef] [PubMed]

34. Mei, Q.; Gu, Y.; Xiang, L.; Baker, J.S.; Fernandez, J. Foot pronation contributes to altered lower extremity loading after long distance running. Front. Physiol. 2019, 10, 573. [CrossRef] [PubMed]

35. Okunuki, T.; Koshino, Y.; Yamanaka, M.; Tsutsumi, K.; Igarashi, M.; Samukawa, M.; Saitoh, H.; Tohyama, H. Forefoot and hindfoot kinematics in subjects with medial tibial stress syndrome during walking and running. J. Orthop. Res. 2019, 37, 927-932. [CrossRef] [PubMed]

36. Rees, D.; Younis, A.; MacRae, S. Is there a correlation in frontal plane knee kinematics between running and performing a single leg squat in runners with patellofemoral pain syndrome and asymptomatic runners? Clin. Biomech. 2019, 61, 227-232. [CrossRef]

37. Brown, A.M.; Zifchock, R.A.; Hillstrom, H.J. The effects of limb dominance and fatigue on running biomechanics. Gait Posture 2014, 39, 915-919. [CrossRef]

38. Ceyssens, L.; Vanelderen, R.; Barton, C.; Malliaras, P.; Dingenen, B. Biomechanical risk factors associated with running-related injuries: A systematic review. Sports Med. 2019, 49, 1095-1115. [CrossRef] 